Research

Elsevier Editorial System(tm) for Fisheries

Manuscript Draft

Manuscript Number: FISH7715R2

Title: Size selection of Nephrops norvegicus (L.) in commercial creel fishery in the Mediterranean sea

Article Type: Research Paper

Keywords: Nephrops norvegicus; creel selectivity; unpaired data

Corresponding Author: Mr. Jure Brcic, Ph.D.

Corresponding Author's Institution: University of Split

First Author: Jure Brcic, Ph.D.

Order of Authors: Jure Brcic, Ph.D.; Bent Herrmann, Ph.D.; Marina Mašanović; Mateja Baranović; Svjetlana Krstulović Šifner, Ph.D.; Frane Škeljo, Ph.D.

Manuscript Region of Origin: CROATIA 


\section{Size selection of Nephrops norvegicus (L.) in commercial creel fishery in the}

\section{Mediterranean Sea}

3 Jure Brčić $^{1 *}$, Bent Herrmann ${ }^{2,3}$, Marina Mašanović ${ }^{1}$, Mateja Baranović ${ }^{1}$, Svjetlana Krstulović

$4 \quad \check{S}_{\text {ifner }}{ }^{1}$, Frane Škeljo ${ }^{1}$

${ }^{1}$ University of Split, University Department of Marine Studies, Ruđera Boškovića 37, 21000 Split (Croatia)

${ }^{2}$ SINTEF Fisheries and Aquaculture, Fishing Gear Technology, Willemoesvej 2, 9850 Hirtshals (Denmark)

${ }^{3}$ University of Troms $\varnothing$, Breivika, N-9037 Troms $\varnothing$ (Norway)

*: Corresponding author. Tel.: +385 21510 197; E-mail address: jure.brcic@unist.hr

\section{Abstract}

11 In the Mediterranean Sea Nephrops (Nephrops norvegicus) is predominantly caught with bottom trawls, but it is also harvested with creels. While the size selection of Nephrops in

13 bottom trawls is well documented, there is no previous information on creel size selection for 14 this species. Therefore, sea trials were carried out to assess the selective properties of commercial creels with $41 \mathrm{~mm}$ mesh size netting mounted as a square mesh netting as prescribed by the legislation. Creel size selection was assessed for Nephrops and two main crustacean bycatch species: mantis shrimp (Squilla mantis) and blue-leg swimming crab (Liocarcinus depurator). The influence of the soak time on creel selectivity was also investigated, and no significant difference was detected between one and two day soak times. The average carapace length of a crustacean with $50 \%$ probability of being retained (L50) was

$2131.69 \mathrm{~mm}$ for Nephrops, which is $59 \%$ larger than the minimum landing size (MLS) set by 22 the fishery regulation, therefore demonstrating a mismatch between MLS and gear selectivity 23 in this fishery. Comparison of creel selectivity obtained in our study with the historical results 24 obtained from commercial bottom trawl selectivity studies for Nephrops in the Mediterranean 
Sea demonstrated that the creel L50 was significantly higher than in the trawl fishery, this implies that creel fishery is targeting larger Nephrops than trawl fishery.

\section{Introduction}

Nephrops (Nephrops norvegicus) is the most valuable crustacean species caught in the EU waters, targeted by both bottom trawl and creel commercial fishery (Leocádio et al. 2012). Total annual catch in the Mediterranean varied from 2470 t to $5752 \mathrm{t}$ in the last decade (EUROSTAT: http://ec.europa.eu/eurostat/data/database). Nephrops is mainly targeted by bottom trawlers and the size selection of trawls for Nephrops in the Mediterranean Sea is well documented (Sardà et al. 1993; Guijarro \& Massutì 2006; Sala et al. 2008; Sala \& Lucchetti 2010).

With the recent reform of Common Fisheries Policy (CFP), EU encourages alternative types of fishing methods that increase size and species selectivity or minimise the negative impact of fishing activities on the marine environment (Regulation (EU) No 1380/2013). One of such alternatives is fishing with creels, which are generally considered as a fishing gear with low impact on the non-target species (Eno et al. 2001; Morello et al. 2009) and benthic fauna in general (Eno et al. 2001; Adey 2007; Johnson et al. 2013). Other advantages of creel fishing for Nephrops include reduced quantity of the discards (Eno et al. 2001; Morello et al. 2009) and higher market value, usually because individuals are larger and in better condition (Eriksson 2006; Ridgway et al. 2006). The availability of Nephrops to trawls is known to be dependent on their burrow emergence rhythms and therefore an efficient harvesting requires synchronization with Nephrops diel activity (Aguzzi \& Sardà 2008; Morello et al. 2009, Katoh et al. 2013). For the creel fishery to be effective, the creels need to be soaked for at least one day to cover the dial periods with high activity for Nephrops. 
In Croatia, creel fishery for Nephrops is open throughout the year in all fishing zones, but in

50 practice it is confined to the internal waters during the period when trawling is prohibited in the area. The creels are set in a longline system from small artisanal vessels, with minimal allowed mesh size of either $36 \mathrm{~mm}$ or $40 \mathrm{~mm}$, depending on the fishing zone (Anonymus 2015).

The creel capture process involves attracting the target species, luring it inside using the bait and keeping it in captivity until the retrieval. Once inside the creel, Nephrops can escape if they are small enough to exit through the creel meshes. The main goal of this study was to estimate the size selectivity of commercial creels targeting Nephrops in the Mediterranean Sea and to investigate if the creel size selectivity is well balanced with the Nephrops minimum landing size. From the previous study conducted by Morello et al. (2009) in the Adriatic Sea, we know that the size distributions of Nephrops caught by creels and the bottom trawl targeting Nephrops differs, indicating that there could be a difference in size selectivity between the two gears. This study also aims to investigate if there is any difference in size selectivity between the two gears and quantifies such difference. Besides these main goals, we also intended to investigate if the increase in soak time from one to two days influences creel size selectivity and to assess the creel size selectivity for the two main crustacean bycatch species in this fishery: mantis shrimp (Squilla mantis) and the blue-leg swimming crab (Liocarcinus depurator).

\section{Material and methods}

\subsection{Experimental design}

71 Experimental fishing was conducted in the eastern Adriatic Sea (Fig. 1) during the period of 7226 May - 5 July. 


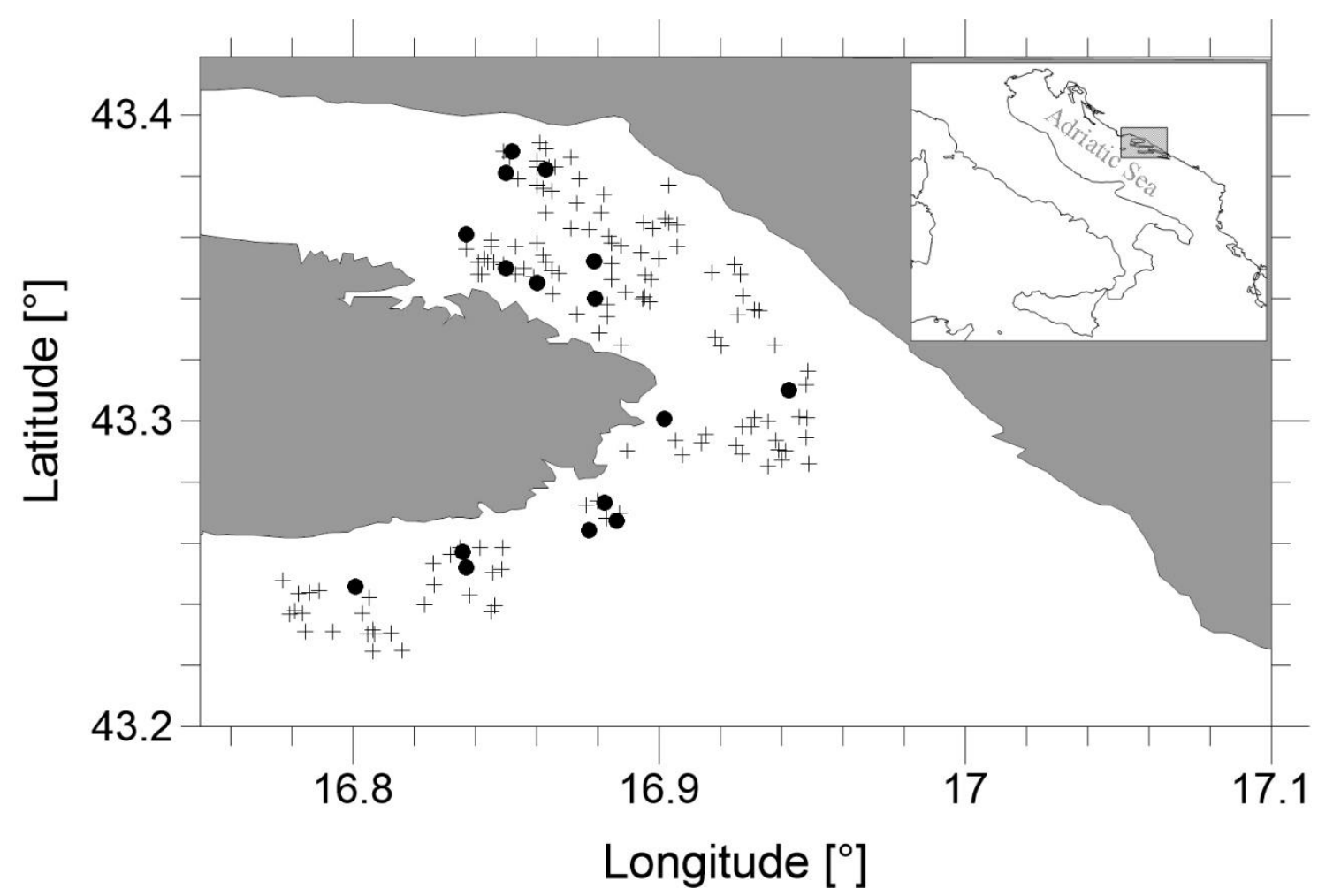

74 Fig. 1. Map of the sampling area showing position of test (crosses) and control (circles) creel sets.

Fishing was carried out from a small commercial fishing vessel (LOA $6.90 \mathrm{~m}, 84 \mathrm{hp}$ ) normally operating in the study area. We tested the size selectivity of commercial creels with mean mesh size of $41 \mathrm{~mm}$ and standard deviation of $0.72 \mathrm{~mm}$ knotless polyamide netting, hereafter called the test creels. To do so we simultaneously fished with the creels rigged with a $12 \mathrm{~mm}$ mesh size polyamide netting to prevent the small crustaceans from escaping after entering, hereafter called the control creels. Both test and control creels consisted of a rectangular plastic coated metal frame (length $700 \mathrm{~mm}$, width $450 \mathrm{~mm}$, depth $265 \mathrm{~mm}$ and $\varnothing$ $5 \mathrm{~mm}$ ) on which the netting was mounted in a way to obtain a square mesh shape, as prescribed by the legislation. The creels had two oval funnel entrances made of the same netting and placed opposite each other on the short sides of the creel (Fig. 2). 

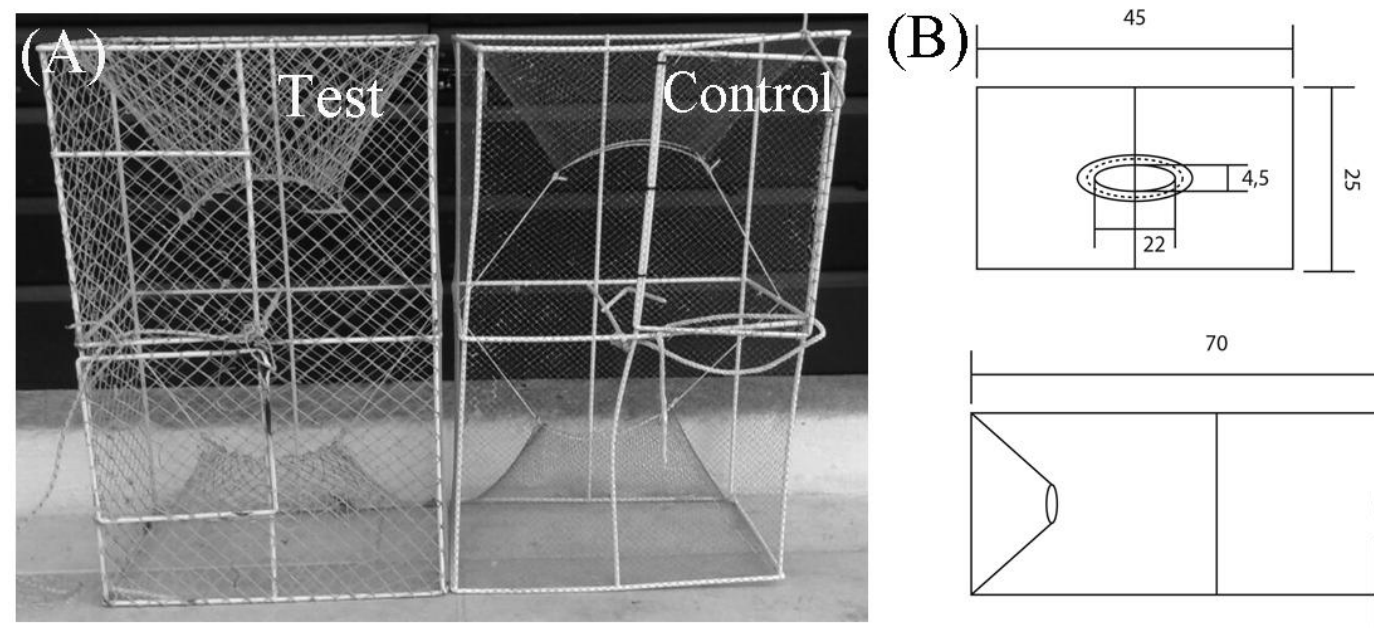

\section{(C)}
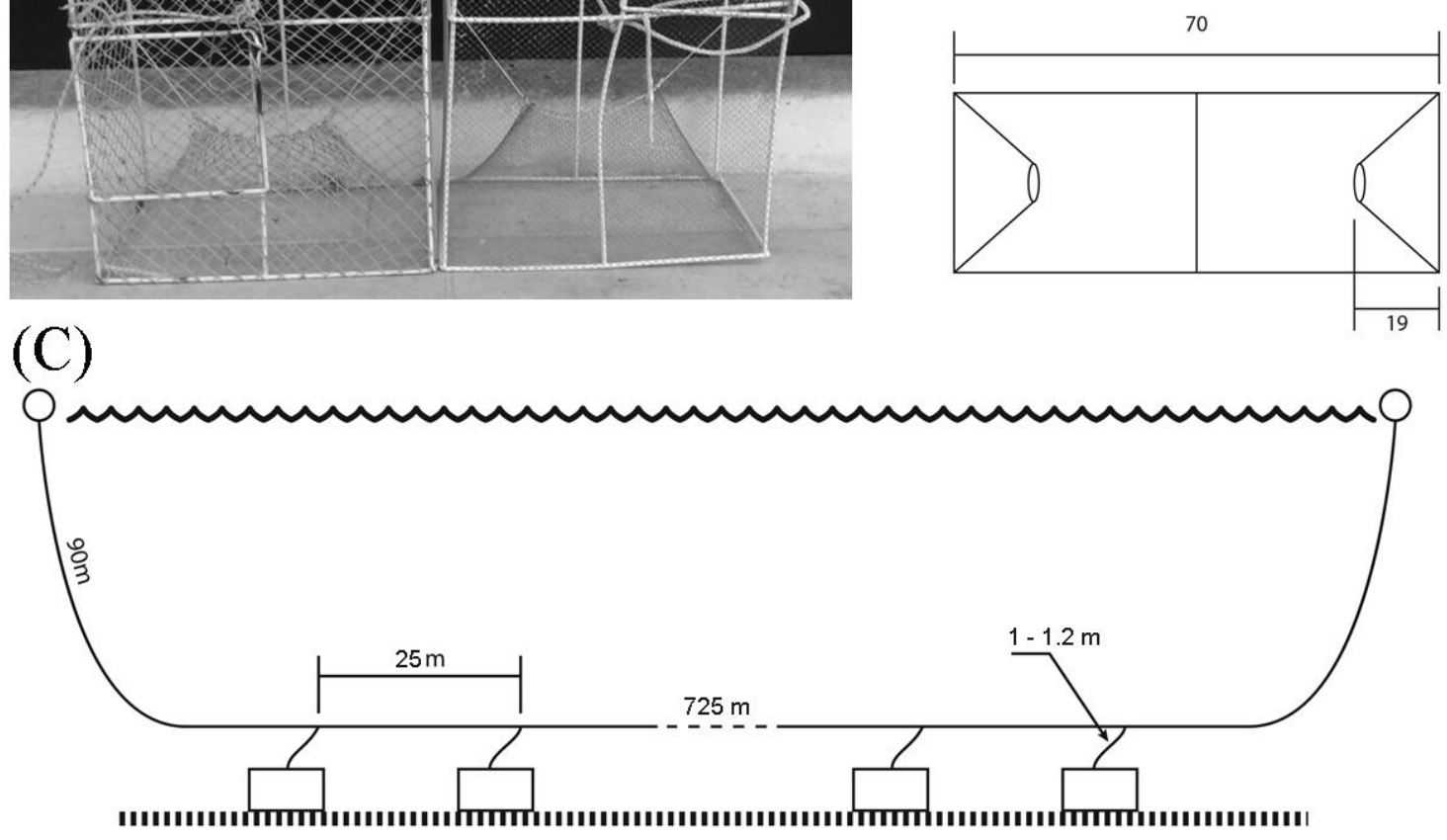

Fig. 2. Photo (A) and technical drawing of the creels (B) used in the study and the illustration of the deployment in the longline system (C).

During fishing, the creels were baited with pieces of Mediterranean horse mackerel (Trachurus mediterraneus) placed halfway between the entrances. The average weight of the bait per creel was $43.29 \pm 11.33 \mathrm{~g}$. The creels were set in longlines with 30 creels attached to the main line (Fig. 2). The distance between the consecutive creels in longline was $25 \mathrm{~m}$. On each fishing day, 12 test longlines, each equipped with 30 identical test creels and 1 control longline equipped with 30 identical control creels were fished. The catch of one longline was considered as the base unit for the subsequent data analysis. This experiment design was chosen because the catch from each longline on each fishing day could be stored in one basket 
for subsequent sorting and measuring. Further, the catch from 30 identical creels treated as

100 one catch unit, ensured sufficient individuals to enable including all catch units in the subsequent analysis which else would not be possible, considering the relative low catch rates in individual creels in the fishery.

103

Both test and control longlines were deployed following the typical commercial fishing practice, with the control longline deployed randomly within the fishing area (Fig 1). Creels were usually set in the early morning hours and retrieved after one or two days if the local weather conditions permitted. The average duration of the shooting phase for each longline nearest $\mathrm{mm}$, and the count number for each $1 \mathrm{~mm}$ length group was registered.

\subsection{Selectivity data analysis}

114 The analysis was conducted separately for each of the three species and separately for

115 deployments with one and two day soak times. The deployments with three and four days

116 soak time were excluded from the analysis because of insufficient number of deployments.

117 The data were analysed using the software tool SELNET (Herrmann et al. 2012) and the 118 method described below. Owing to the experimental design, the catch data from the test and 119 control longlines was not collected in pairs and can be regarded as unpaired, with unequal 120 number of test and control longline deployments. Since there is no obvious way of pairing the

121 catch data from individual test and control longline deployments, the average size selectivity

122 for the test creels was estimated by adopting the method described in Sistiaga et al. (2016a), 
123

124

126

$-\sum_{l}\left\{\sum_{i=1}^{a} n T_{l i} \times \ln \left(\frac{S P \times r(l, v)}{S P \times r(l, v)+1-S P}\right)+\sum_{j=1}^{b} n C_{l j} \times \ln \left(1.0-\frac{S P \times r(l, v)}{S P \times r(l, v)+1-S P}\right)\right\}$

where $n T_{l i}$ and $n C_{l i}$ represent the number of caught individuals of each length class $l$ retained

128 by the $\mathrm{i}$-th deployment of a test longline and j-th deployment of a control longline. $a$ and $b$ represent the total number of deployments of the test and control longlines, respectively. $S P$ is

130 the split factor quantifying the sharing of the total catch between the test and the control

131 longlines (Sistiaga et al. 2016a). Assuming on average an equal entry probability (fishing 132 power) between test and control creels, the expected value for $S P$ should be $a /(a+b)$.

133 Minimizing Eq. (1) is equivalent to maximizing the likelihood for the observed experimental 134 data. $\boldsymbol{v}$ is a vector of parameters describing the size selection model $r(l, v)$. Since the test creels 135 were constructed with the single fixed shaped mesh size, we assumed that the creel size 136 selection can be described by the standard logit model (Wileman et al. 1996) as formerly applied by Xu \& Millar (1993) and Winger \& Walsh (2011) to model size selection of crustaceans in creel fishery:

$r(l, \boldsymbol{v})=\frac{\exp \left(\frac{\ln (9)}{S R} \times(l-L 50)\right)}{1.0+\exp \left(\frac{\ln (9)}{S R} \times(l-L 50)\right)}$

140 with selection parameters $v=(L 50, S R) . L 50$ is the carapace length or width of a crustacean 141 with a $50 \%$ probability of being retained, while $S R$ is the difference in carapace length or 142 width of crustaceans having respectively $75 \%$ and $25 \%$ probability of being retained by the 143 test creel, conditioned they entered the creel. Hence, estimation of the average test creel size 144 selection assuming a logit size selection model involves finding the values for the parameters 
$145 L 50, S R$ and SP that minimizes (1) conditioned by the collected catch data. The ability of this

146 size selection model to describe the experimental data was evaluated based on the p-value,

147 which quantifies the probability of obtaining by coincidence at least as big a discrepancy

148 between the experimental data and the model as observed, assuming that the model is correct.

149 Therefore, the p-value calculated based on the model deviance and the degrees of freedom

150 should not be $<0.05$ for the logit model to describe the experimental data sufficiently well

151 (Wileman et al. 1996).

152 The confidence limits for the size selection curve and the associated selection parameters

153 were estimated using the double bootstrapping method for unpaired data described in Sistiaga

154 et al. (2016a). This method accounted for between-deployment variation in the availability of

155 crustaceans and creel size selection by selecting $a$ deployments with replacement from the

156 pool of test longlines deployed and b deployments with replacement from the pool of control

157 longlines deployed during each bootstrap repetition. Within-deployment uncertainty in the

158 size structure of the catch data was accounted for by randomly selecting crustaceans with

159 replacement from each of the selected longlines separately. The number of crustaceans

160 selected from each deployment was the same as the number of crustaceans caught with that

161 deployment of the longline. For each species, we performed 1000 bootstrap repetitions and

162 calculated the Efron 95\% (Efron 1982) confidence limits for the size selection curve and the

163 associated parameters.

164 The above described analysis was performed separately for deployments with one and two

165 day soak times to check if the confidence intervals between the size selectivity curves overlap.

166 In case they do for all length classes it means that there is no significant difference between

167 the selectivity curves (Wienbeck et al. 2014; Brčić et al. 2015), and an additional analysis

168 based on the data aggregated for all the deployments independent of soak time will be

169 conducted. 
171 The estimated creel size selection for Nephrops was compared with the minimum landing size

172 (MLS) specified at $20 \mathrm{~mm}$ carapace length (Council Regulation (EC) No 1967/2006) to check

173 if the commercial creels have the desired exploitation pattern i.e. do they release all

174 individuals below MLS while retaining all the individuals above the MLS.

175 In addition, exploitation pattern of creels and bottom trawls was compared based on the

176 historical commercial bottom trawl size selectivity data obtained from the literature for the 40

$177 \mathrm{~mm}$ square mesh and $50 \mathrm{~mm}$ diamond mesh codends from the Mediterranean Sea (Council

178 Regulation (EC) No 1967/2006) (Table 1).

179

180 Table 1. Size selection of Nephrops in commercial Mediterranean bottom trawl fishery; MC:

181 mesh configuration (SM: square mesh; DM: diamond mesh); L50: carapace length of a

182 crustacean with a 50\% probability of being retained; SR: Selection range; Values in brackets

183 represent $95 \%$ confidence intervals; *Nominal mesh size

\begin{tabular}{lllll}
\hline & $\begin{array}{l}\text { Mesh } \\
\text { size }\end{array}$ & & & \\
MC & {$[\mathrm{mm}]$} & L50 [mm] & SR [mm] & Reference \\
\hline SM & $40^{*}$ & $24.1(23.3-24.7)$ & 5.9 & Stergiou et al. (1997) \\
SM & $40^{*}$ & $24.6(24.3-25.3)$ & 1.5 & Guijarro \& Massutì (2006) \\
SM & 38.7 & 19.1 & 3.7 & Sala et al. (2008) \\
SM & 43.3 & $19.3(19.2-19.4)$ & 7.5 & Sala \& Lucchetti (2010) \\
SM & 43.3 & $20.7(20.5-21.0)$ & $6.2(6.0-6.5)$ & Sala \& Lucchetti (2010) \\
DM & 51.8 & $20.5(19.3-21.5)$ & 7.6 & Mytilineou et al. (1998) \\
\hline
\end{tabular}

184

185

\section{Results}

187 A total of 216 test and 18 control longlines were fished during 18 daily fishing trips (Table 2). 
188 Table 2. Number of individuals caught in Test (nT) and Control (nC) creels; NEP: Nephrops;

189 MTS: mantis shrimp; IOD: blue-leg swimming crab.

\begin{tabular}{cccccccc}
\hline Date & $\begin{array}{c}\text { Soak } \\
\text { time } \\
\text { [day] }\end{array}$ & nT & nC & nT & nC & nT & nC \\
\hline $26 / 05 / 2016$ & 1 & 46 & 3 & 38 & 13 & 100 & 25 \\
$27 / 05 / 2016$ & 1 & 46 & 12 & 28 & 6 & 84 & 28 \\
$28 / 05 / 2016$ & 1 & 50 & 5 & 43 & 12 & 106 & 17 \\
$31 / 05 / 2016$ & 2 & 54 & 8 & 26 & 5 & 81 & 27 \\
$03 / 06 / 2016$ & 1 & 40 & 1 & 27 & 6 & 98 & 28 \\
$04 / 06 / 2016$ & 1 & 48 & 2 & 49 & 8 & 87 & 24 \\
$05 / 06 / 2016$ & 1 & 32 & 6 & 29 & 4 & 90 & 20 \\
$07 / 06 / 2016$ & 1 & 36 & 3 & 39 & 4 & 60 & 23 \\
$08 / 06 / 2016$ & 1 & 25 & 1 & 40 & 17 & 79 & 6 \\
$14 / 06 / 2016$ & 1 & 40 & 5 & 51 & 15 & 68 & 12 \\
$18 / 06 / 2016$ & 2 & 32 & 7 & 25 & 2 & 67 & 10 \\
$20 / 06 / 2016$ & 2 & 41 & 6 & 41 & 5 & 59 & 17 \\
$22 / 06 / 2016$ & 2 & 29 & 2 & 26 & 12 & 54 & 8 \\
$26 / 06 / 2016$ & 2 & 28 & 9 & 50 & 10 & 51 & 9 \\
$29 / 06 / 2016$ & 2 & 28 & 2 & 50 & 5 & 62 & 14 \\
$01 / 07 / 2016$ & 2 & 42 & 7 & 48 & 11 & 83 & 11 \\
$03 / 07 / 2016$ & 2 & 43 & 4 & 51 & 7 & 84 & 14 \\
$05 / 07 / 2016$ & 2 & 40 & 1 & 39 & 7 & 99 & 10 \\
\hline
\end{tabular}

190

191

192 The average water depth $( \pm \mathrm{SD})$ in the study area was $74.7( \pm 2.9 \mathrm{~m})$. Altogether, 784

193 Nephrops, 849 mantis shrimps and 1715 blue-leg swimming crabs were caught and measured

194 during the experimental fishing. The mean number of Nephrops individuals caught per

195 longline $( \pm$ SD) was $4.96( \pm 2.60)$ and $4.67( \pm 3.12)$ for test and control longlines,

196 respectively. Carapace length (CL) of retained individuals ranged from 31 to $65 \mathrm{~mm}$ in test

197 and from 20 to $62 \mathrm{~mm}$ in control. The average catch rate of mantis shrimp was $4.79( \pm 2.45)$

198 in test and $8.28( \pm 4.23)$ in control longlines. The CL ranged from 26 to $47 \mathrm{~mm}$ in test and

199 from 20 to $41 \mathrm{~mm}$ in control. Blue-leg swimming crab had the highest average catch rate,

200 both per test and control longlines, $9.74( \pm 4.40)$ and $16.83( \pm 7.45)$, respectively. The

201 carapace width (CW) of retained individuals ranged from 22 to $59 \mathrm{~mm}$ in the test and from 20 
202 to $47 \mathrm{~mm}$ in the control longlines. The length distributions of analysed species in test and 203 control longlines are shown in Fig. 3.
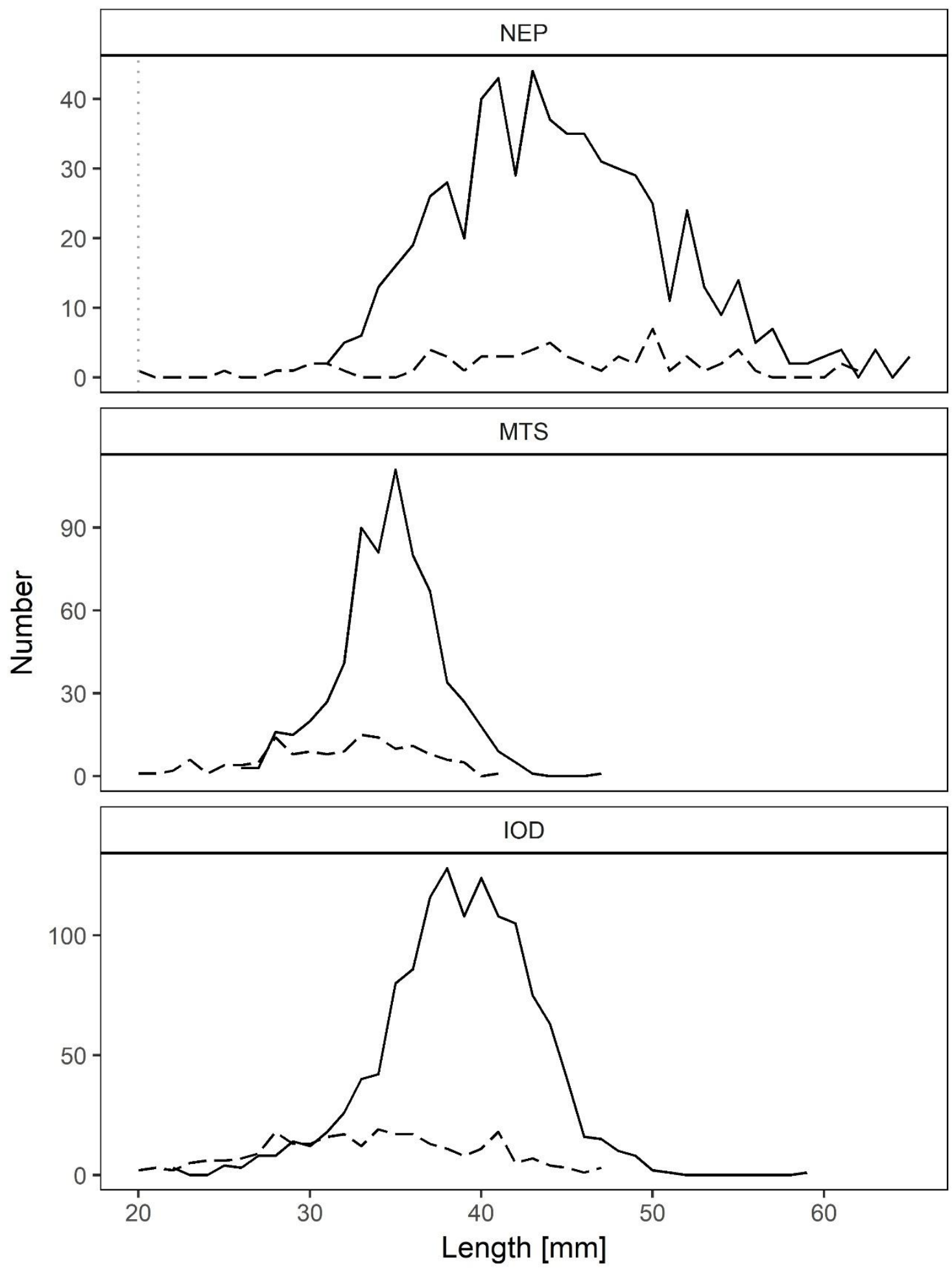
205 Fig. 3. Length distribution of analysed species in test (solid line) and control (dashed line) 206 creels; Vertical dotted line: Minimum Landing Size (MLS); Length represents carapace length 207 for NEP and MTS and carapace width for IOD; NEP: Nephrops; MTS: mantis shrimp; IOD: 208 blue-leg swimming crab.

210 Fig. 4 shows the fit of the logit selection curve to the experimental catch data for the test and 211 control creels summed over deployments with respectively one (black) and two day (grey) 212 soak times. 

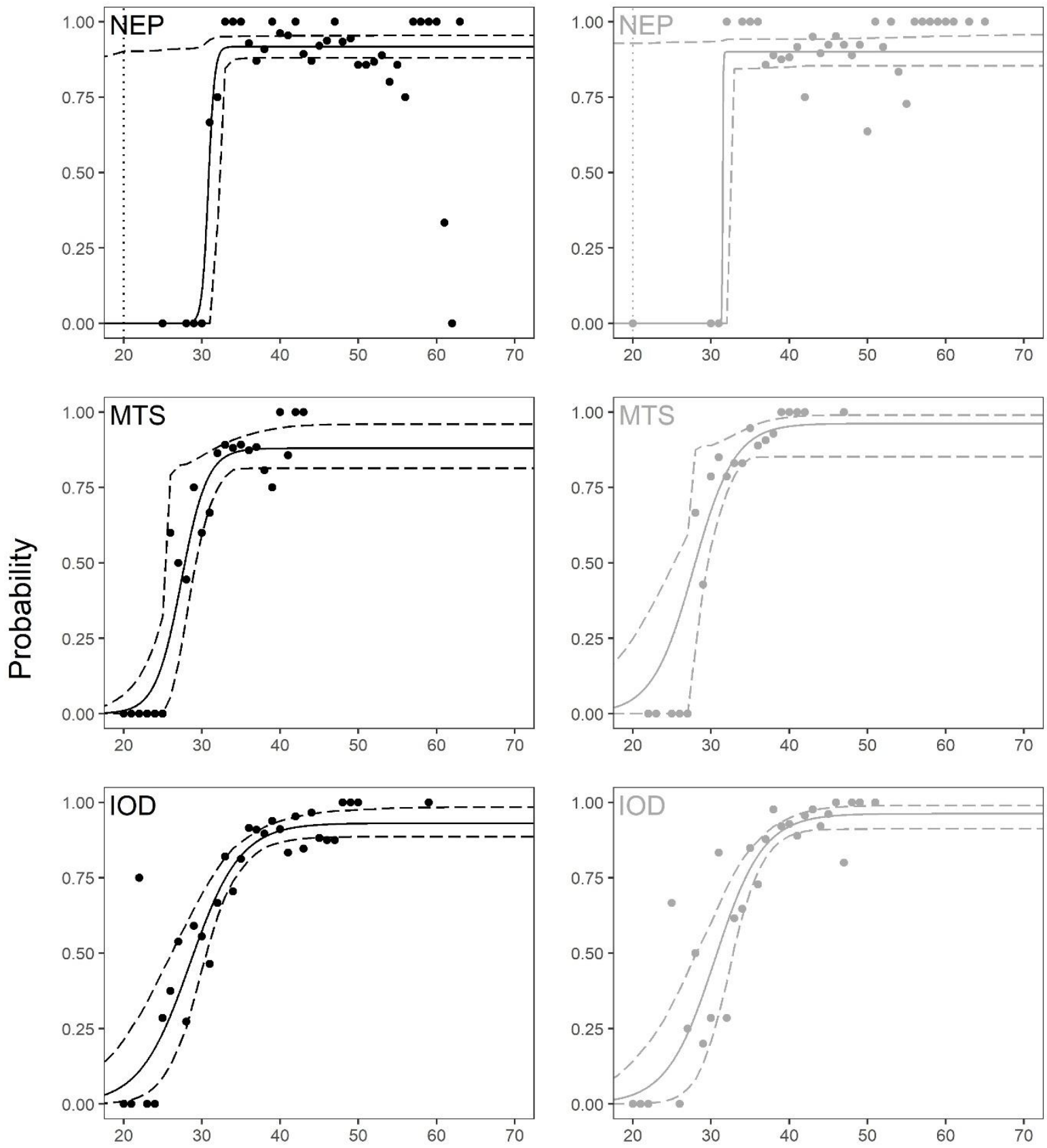

215 Fig. 4. Catch sharing curves (solid lines) with their respective 95\% confidence intervals 216 (dashed lines) for 1 day soak time (black) and 2 day soak time (grey). The solid circles 217 represent the average experimental rates for each length class. A vertical grey dotted line 218 represents MLS. Length represents carapace length for NEP and MTS and carapace width for IOD; NEP: Nephrops; MTS: mantis shrimp; IOD: blue-leg swimming crab. 
221 It is evident that the modelled catch sharing curve between test and control creels reflects the 222 main trends in the experimental data for all three species. Fit statistics presented in table 3 223 confirm the visual inspection that the logit size selection model describes the experimental 224 data well.

225 Table 3. Average size selectivity and logit model fit statistics. Values in brackets represent 226 95\% confidence intervals; L50: carapace length (for NEP and MTS) or carapace width (for 227 IOD) at which 50\% of the individuals are retained; SR: Selection range; SP: Split factor; 228 DOF: degrees of freedom; NEP: Nephrops; MTS: mantis shrimp; IOD: blue-leg swimming 229 crab.

\begin{tabular}{cllll}
\hline $\begin{array}{c}\text { Soak } \\
\text { time } \\
\text { [day] }\end{array}$ & NEP & MTS & IOD \\
\hline 1 & L50 [mm] & $31.82(17.76-33.18)$ & $30.86(25.96-36.86)$ & $37.03(33.14-46.87)$ \\
& SR [mm] & $0.89(0.1-2.65)$ & $3.63(0.10-6.16)$ & $7.05(4.54-10.80)$ \\
& SP & $0.92(0.88-0.95)$ & $0.88(0.81-0.95)$ & $0.93(0.88-0.98)$ \\
& p-value & 0.482 & 0.682 & 0.0529 \\
& Deviance & 33.71 & 17.47 & 42.29 \\
& DOF & 34 & 21 & 29 \\
& & & & \\
2 & L50 [mm] & $31.59(0.1-61.33)$ & $36.37(27.57-48.00)$ & $40.58(35.50-49.51)$ \\
& SR [mm] & $0.10(0.1-21.57)$ & $5.81(0.1-11.03)$ & $6.77(3.73-10.34)$ \\
& SP & $0.90(0.85-0.99)$ & $0.96(0.85-0.99)$ & $0.96(0.91-0.99)$ \\
& p-value & 0.8790 & 0.6711 & 0.238 \\
& Deviance & 22.13 & 14.87 & 30.74 \\
& DOF & 31 & 18 & 26 \\
\hline
\end{tabular}

231 From Fig. 5 it is clear that the confidence intervals of the selectivity curves obtained 232 separately for deployments with one (black) and two (grey) day soak times completely 233 overlap, showing no significant effect of the soak time on the creel size selectivity. This 234 allowed us to perform the additional analysis based on all deployments combined. 

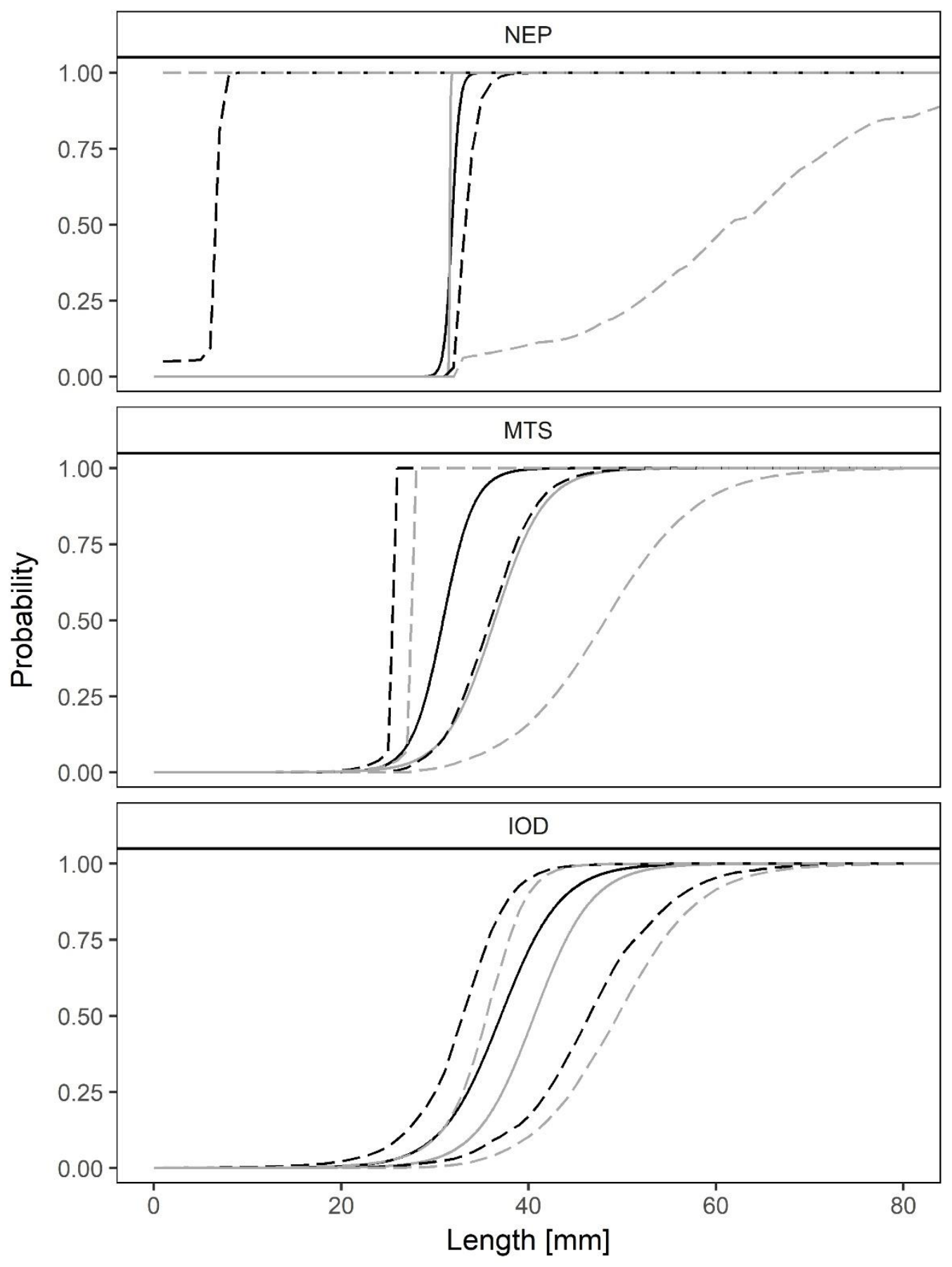

236 Fig. 5. Pairwise comparison between the average selectivity curves (solid lines) for 1 day 237 soak time (black) and 2 day soak time (grey). Dashed lines represent $95 \%$ confidence 238 intervals. Length represents carapace length for NEP and MTS and carapace width for IOD; 239 NEP: Nephrops; MTS: mantis shrimp; IOD: blue-leg swimming crab. 
241 Fig. 6 shows the fit of the logit selection curve to the experimental catch data for the test and 242 control creels summed over all deployments. From the figure it is evident that the modelled 243 catch sharing curve between test and control creels reflects the main trends in the 244 experimental data for all three species (left column in Fig. 6).
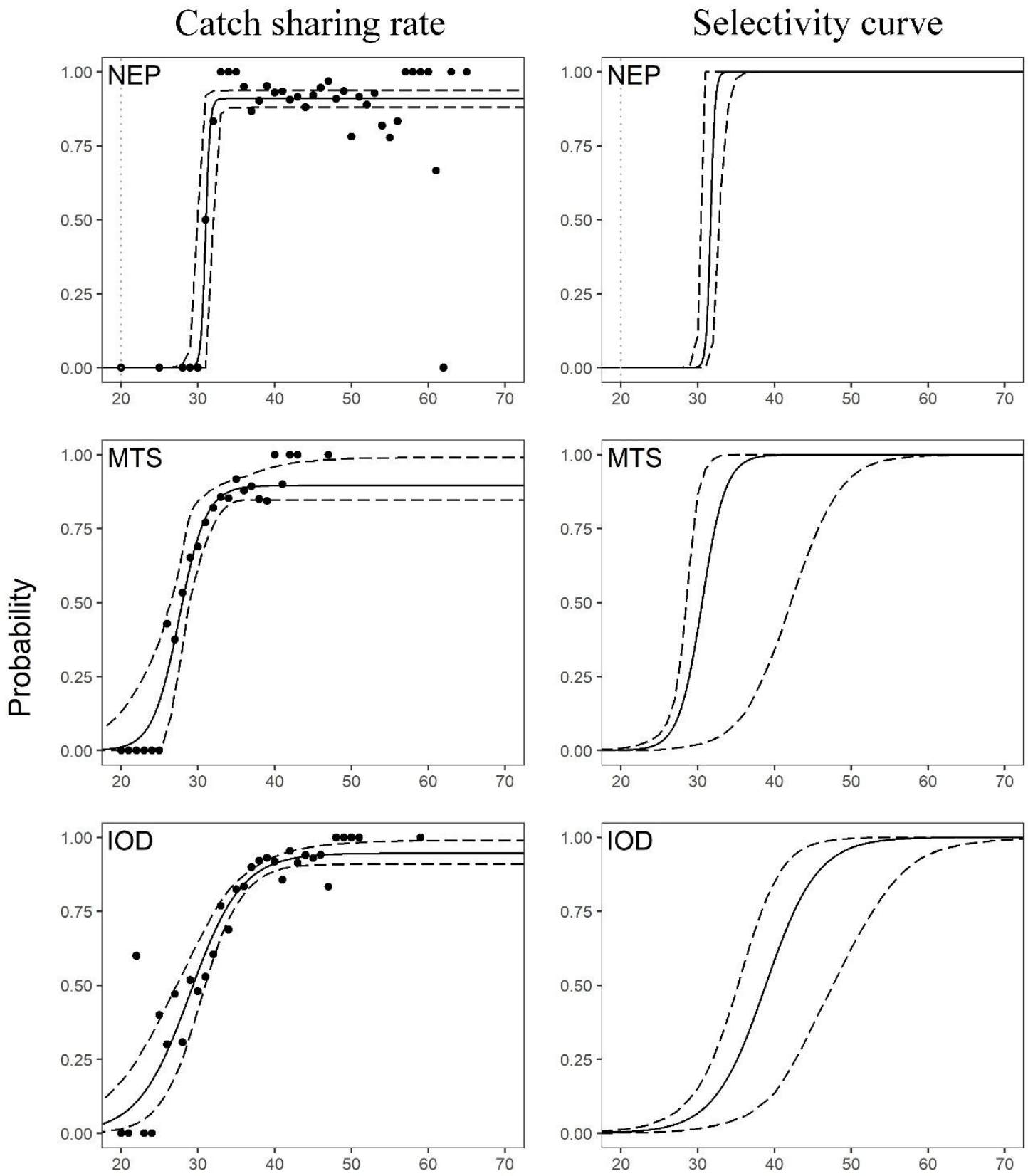

\section{Length [mm]}

246 Fig. 6. Catch sharing rate and selection curves (solid lines) with their respective 95\% 247 confidence intervals (dashed lines). The solid black circles represent the average experimental 
rates for each length class. A vertical grey dotted line represents MLS. Length represents

249 carapace length for NEP and MTS and carapace width for IOD; NEP: Nephrops; MTS:

250 mantis shrimp; IOD: blue-leg swimming crab.

252 Fit statistics confirm the visual inspection (Table 4), indicating that the logit model describes

253 the experimental data well. The SP values are close to the expected value 0.92 $254 \quad(=216 /(216+18))$ for all three species.

Table 4. Average size selectivity and logit model fit statistics. Values in brackets represent 95\% confidence intervals; L50: carapace length (for NEP and MTS) or carapace width (for

258 IOD) at which 50\% of the individuals are retained; SR: Selection range; SP: Split factor;

259 MLS: minimum landing size; DOF: degrees of freedom; NEP: Nephrops; MTS: mantis

260 shrimp; IOD: blue-leg swimming crab.

\begin{tabular}{llll}
\hline & NEP & MTS & IOD \\
\hline L50 [mm] & $31.69(30.10-32.80)$ & $31.48(28.80-43.13)$ & $38.85(35.15-48.70)$ \\
SR [mm] & $0.64(0.10-1.41)$ & $3.82(1.61-7.80)$ & $7.41(5.30-10.79)$ \\
SP & $0.91(0.88-0.94)$ & $0.90(0.85-0.99)$ & $0.95(0.91-0.99)$ \\
p-value & 0.6148 & 0.9345 & 0.1403 \\
Deviance & 32.94 & 12.95 & 38.38 \\
DOF & 36 & 22 & 30 \\
\hline
\end{tabular}

261

Nephrops is the only investigated species with minimum landing size (MLS) set by the

264 fishery regulation (Council Regulation (EC) No 1967/2006). All individuals caught in the test 265 creels were above the MLS, resulting in the average L50 value significantly above the MLS 266 (Table 4). The average value of L50 obtained in this study was 59\% larger than the MLS, 267 showing a clear mismatch between the species MLS and the gear regulation in this fishery. 


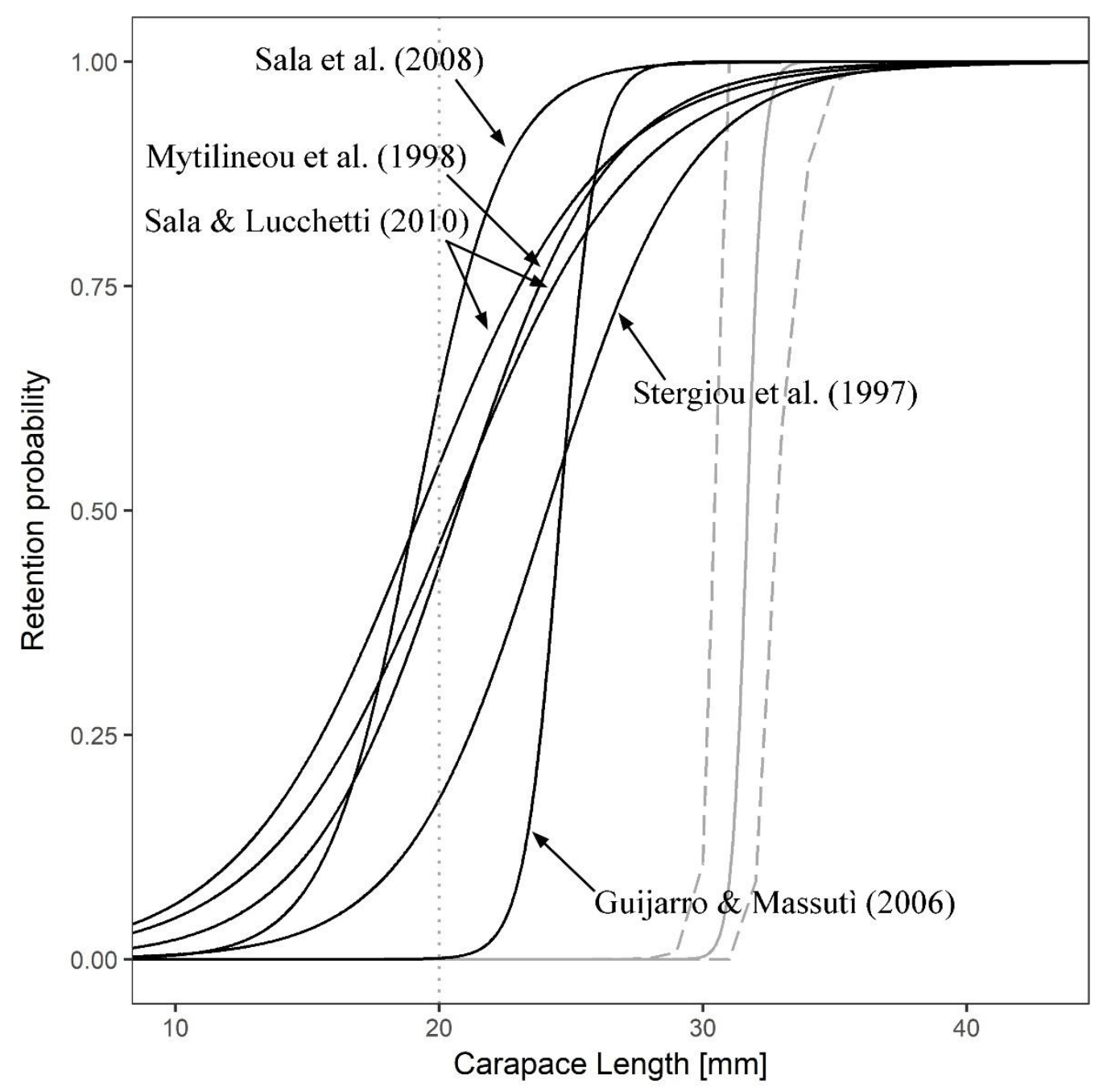

271 Fig. 7. Comparison between creel selection curve with $95 \%$ confidence intervals obtained in 272 this study (grey) and trawl selectivity curves obtained from the literature (black) for

273 Nephrops. A vertical grey dotted line represents MLS.

275 The average L50 obtained for creels was $28.8 \%-65.9 \%$ larger than L50 reported by bottom 276 trawl selectivity studies using either $40 \mathrm{~mm}$ square mesh or $50 \mathrm{~mm}$ diamond mesh codends 277 for Nephrops in the Mediterranean Sea. The SR value obtained in this study was substantially 
smaller $(57.3 \%-91.6 \%)$ than the values reported by the same trawl selectivity studies (Table 4 versus Table 1). For the creel bycatch species mantis shrimp and blue-leg swimming crab the average L50 was respectively $31.48 \mathrm{~mm} \mathrm{CL}$ and $38.85 \mathrm{~mm} \mathrm{CW}$ (Table 4).

\section{Discussion}

Our results are the first to quantify creel size selection for Nephrops, mantis shrimp and blueleg swimming crab. The results did not show any influence of soak time duration on the creel size selectivity for the three analysed species. The average creel L50 value obtained for Nephrops was significantly higher than the MLS prescribed in the legislation, implying a significant deviation from the desired exploitation pattern.

The EU Regulation (Council Regulation (EC) No 1967/2006) defines 40 mm square mesh and $50 \mathrm{~mm}$ diamond mesh as a minimum allowed mesh size for the EU trawlers operating in the Mediterranean basin. The average value of L50 obtained for Nephrops in this study was much larger than those reported by the trawl selectivity studies using both legal codends, emphasizing the difference in exploitation pattern between the gears. This means that creel fishery is targeting larger Nephrops than trawl fishery. The large values of L50 could be explained by the relatively constant mesh shape in creels, whereas in trawls the mesh shape is known to vary as the net is towed through the sea (Krag et al. 2011). This could also be the reason for the low SR value obtained for Nephrops in this study (Table 4), compared to the results from the trawl selectivity studies (Table 1). According to Frandsen et al. (2010), relatively large values for SR obtained for Nephrops in trawls are most likely due to the variation in mesh shape and due to the mix of modes in which Nephrops contacts the netting during the tow. Contrary to trawls, creels lay stationary on the ground, presumably giving Nephrops more time to orientate themselves optimally to escape through the meshes, but 
given that no underwater observations were made in this study it was not possible to confirm

303 this in the field. It is reasonable to assume that since creels have a fixed mesh shape and they

304 lay on the ground for relatively long time, Nephrops has enough time to attempt to escape,

305 which is why the value for SR is probably more related to variation in species cross sectional

306 shape and size between individuals of the same carapace length. On the other hand, Nephrops

307 can easily enter and remain in the creel without trying to escape until the start of the haul back

308 process, when it will have limited time to orientate itself optimally to escape through the 309 meshes.

310 Nephrops like many other animals display agonistic behavior as observed in the wild 311 (Chapman \& Rice 1971) and in the laboratory (Katoh et al. 2008). Moreover group of 312 Nephrops establish dominance hierarchies and dominant lobsters profit of their rank by 313 controlling multiple burrows (Sbragaglia et al. 2017). Because size is always correlated with 314 dominance in group of decapod crustaceans (e.g. Schneider et al. 2001) it is conceivable that 315 the presence of large and dominant Nephrops inside the creel can either prevent small 316 individuals from entering or encourage them to escape through the meshes if they are already 317 inside as demonstrated by Frusher \& Hoenig (2001) for the rock lobster (Jasus edwardsii). 318 Therefore, we cannot exclude that such mechanism may also be an element in explaining the 319 much higher L50 and much lower SR values obtained for the creels compared to the trawls.

320 The new Common Fisheries Policy (Regulation (EU) No 1380/2013) introduced the landing 321 obligation, compelling Mediterranean EU countries to land all catches of species subjected to 322 MLS (Council Regulation (EC) No 1967/2006) no later than January $1^{\text {st }} 2019$. In this study 323 only Nephrops is subjected to MLS, and since no individuals below MLS were caught in the 324 test creels, Croatian creel fishermen should not have any problem with the upcoming landing 325 obligation. That the average selection parameter L50 was larger and the average SR value was 326 smaller for the creels than in the trawl selectivity studies performed with the same mesh size 
is especially interesting if we consider that Nephrops CL at first maturity in the Adriatic Sea

328 is $30 \mathrm{~mm}$ CL (Relini et al. 1998), showing that creel fishery allows Nephrops to spawn at least once before they are caught. However, catching only large animals could negatively impact the exploited population of Nephrops by triggering harvest-induced evolution, but according to Kuparinen \& Festa-Bianchet (2017), a simple reduction in fishing intensity can overcome 332 this potential problem.

333 The aim of this study was to investigate the size selective properties of $40 \mathrm{~mm}$ square mesh 334 creels targeting Nephrops in the eastern Adriatic Sea. For practical reasons, the data were not 335 collected in pairs, which is why the method from Sistiaga et al. (2016a) had to be adopted to 336 estimate average selectivity parameters based on the unpaired data. The uncertainty in the 337 estimation resulting both from between-deployment variation in the availability of target 338 species in the study area, and the uncertainty in the size structure of the catch, was accounted 339 for by using the double bootstrap method previously applied by Sistiaga et al. (2016a) on 340 trawl data. However, the current study is the first to apply this method to creel fishery. Similar 341 approach in the analysis of the unpaired data has been applied by Notti et al. (2016), who 342 compared the catch efficiencies of traditional boat seine and experimental surrounding net 343 without the purse line. Herrmann et al. (2017) used similar methodology to investigate the 344 effect of gear design changes on catch efficiency in Spanish longline fishery, while Sistiaga et 345 al. (2015) and Sistiaga et al. (2016b) used it to analyse the effect of lifting the sweeps in the 346 Norwegian bottom trawl fishery.

347 The method described here can be adopted to other fisheries, while the results are specific for 348 the creel mesh size and mesh opening used in the study area. Further study based on a 349 comparison between the species cross-section geometry and the mesh size and shape could 350 identify specific modes of escapement for each analysed species and explain why the 351 selection curve for Nephrops in the present study is steeper compared to the trawl selectivity 
studies (Fig. 7). In addition, underwater observations could help us better understand the behavioural driven mechanism controlling the creel size selectivity for Nephrops.

\section{Acknowledgments}

The research leading to this paper was funded by the Croatian Ministry of Agriculture. The authors would like to thank Captain Ivo Tomaš for his help with the construction of control creels and for allowing us to follow him during his regular fishing trips. We would also like to thank a crew member Marinko Ivandić for his valuable help during the fieldwork. We are also grateful to Goran Bojanić for the illustrations used in the manuscript and to the anonymous reviewer for the suggestions, which helped us to improve the manuscript significantly.

\section{References}

Adey, JM, 2007. Aspects of the sustainability of creel fishing for Norway lobster, Nephrops norvegicus (L.), on the west coast of Scotland. PhD thesis.

Aguzzi, J, Sardà, F, 2008. A history of recent advancements on Nephrops norvegicus behavioral and physiological rhythms. Reviews in Fish Biology and Fisheries 18, 235248.

Anonymus, 2015. Pravilnik o obavljanju gospodarskog ribolova na moru mrežama stajaćicama, klopkastim, udičarskim i probodnim ribolovnim alatima te posebnim načinima ribolova. Narodne novine br.: 84.

Brčić, J., Herrmann, B., De Carlo, F., Sala, A., 2015. Selective characteristics of a sharkexcluding grid device in a Mediterranean trawl. Fisheries Research 172, 352-360. 
Chapman, CJ, Rice, AL, 1971. Some direct observations on the ecology and behaviour of the Norway lobster, Nephrops norvegicus. Marine Biology 10, 321-329.

Council Regulation (EC) No 1967/2006 of 21 December 2006, concerning management measures for the sustainable exploitation of fishery resources in the Mediterranean Sea, amending Regulation (EEC) No 2847/93 and repealing Regulation (EC) No 1626/94. Official Journal of the European Union L. 409.

Efron, B, 1982. The jackknife, the bootstrap and other resampling plans. SIAM Monograph No. 38, CBSM-NSF.

Eno, NC, MacDonald, DS, Kinnear, JAM, Amos, SC, Chapman, CJ, Clark, RA, Bunker, FSPD, Munro, C, 2001. Effects of crustacean traps on benthic fauna. ICES Journal of Marine Science 58, 11-20.

Eriksson, SP, 2006. Differences in the condition of Norway lobsters (Nephrops norvegicus (L.)) from trawled and creeled fishing areas. Marine Biology Research 2, 52-58.

EUROSTAT. http://ec.europa.eu/eurostat/data/database (accessed 06 December 2017).

Frandsen, RP, Herrmann, B, Madsen, N, 2010. A simulation-based attempt to quantify the morphological component of size selection of Nephrops norvegicus in trawl codends. Fisheries Research 101, 156-167.

Frusher, SD, Hoenig, JM, 2001. Impact of lobster size on selectivity of traps for southern rock lobster (Jasus edwardsii). Canadian Journal of Fisheries and Aquatic Sciences 58, 24822489.

Guijarro, B, Massutì, E, 2006. Selectivity of diamond- and square-mesh codends in the deepwater crustacean trawl fishery off the Balearic Islands (western Mediterranean). ICES Journal of Marine Science 63, 52-67.

Herrmann, B, Sistiaga, M, Nielsen, KN, Larsen, RB, 2012. Understanding the size selectivity of redfish (Sebastes spp.) in North Atlantic trawl codends. Journal of Northwest Atlantic fishery science 44, 1-13.

Herrmann, B, Sistiaga, M, Rindahl, L, Tatone, I, 2017. Estimation of the effect of gear design changes in catch efficiency: methodology and a case study for a Spanish longline fishery targeting hake (Merluccius merluccius). Fisheries Research 185, 153-160. 
Johnson, MP, Lordan, C, Power, AM, 2013. Chapter Two - Habitat and Ecology of Nephrops norvegicus, in: Johnson M.L., Johnson M.P. (Eds.), Advances in Marine Biology. Academic Press, pp. 27-63.

Katoh, E, Johnson, M, Breithaupt, T, 2008. Fighting behaviour and the role of urinary signals in dominance assessment of Norway lobsters, Nephrops norvegicus. Behaviour 145, 1447-1464.

Katoh, E, Sbragaglia, V, Aguzzi, J, Breithaupt, T, 2013. Chapter Three - Sensory Biology and Behaviour of Nephrops norvegicus, in: Johnson M.L., Johnson M.P. (Eds.), Advances in Marine Biology. Academic Press, pp. 65-106.

Krag, LA, Herrmann, B, Madsen, N, Frandsen, RP, 2011. Size selection of haddock (Melanogrammus aeglefinus) in square mesh codends: A study based on assessment of decisive morphology for mesh penetration. Fisheries Research 110, 225-235.

Kuparinen, A. \& Festa-Bianchet, M. (2017). Harvest-induced evolution: insights from aquatic and terrestrial systems. Philos. Trans. R. Soc. Lond. B: Biol. Sci. 372.

Leocádio, AM, Whitmarsh, D, Castro, M, 2012. Comparing Trawl and Creel Fishing for Norway Lobster (Nephrops norvegicus): Biological and Economic Considerations. PLoS ONE 7, e39567.

Morello, EB, Antolini, B, Gramitto, ME, Atkinson, RJA, Froglia, C, 2009. The fishery for Nephrops norvegicus (Linnaeus, 1758) in the central Adriatic Sea (Italy): Preliminary observations comparing bottom trawl and baited creels. Fisheries Research 95, 325-331.

Mytilineou, C, Politou, CY, Fourtouni, A, 1998. Trawl selectivity studies on Nephrops norvegicus (L.) in the eastern Mediterranean Sea. Scientia Marina 62, 107-116.

Notti, E, Brčić, J, Carlo, FD, Herrmann, B, Lucchetti, A, Virgili, M, Sala, A, 2016. Assessment of the Relative Catch Performance of a Surrounding Net without the Purse Line as an Alternative to a Traditional Boat Seine in Small-Scale Fisheries. Marine and Coastal Fisheries 8, 81-91.

Regulation (EU) No 1380/2013 of the European Parliament and of the Council of 11 December 2013 on the Common Fisheries Policy, amending Council Regulations (EC) No 1954/2003 and (EC) No 1224/2009 and repealing Council Regulations (EC) No 
2371/2002 and (EC) No 639/2004 and Council Decision 2004/585/EC. Official Journal of the European Union L 354.

Relini, LO, Zamboni, A, Fiorentino, F, Massi, D, 1998. Reproductive patterns in Norway lobster Nephrops norvegicus (L.), (Crustacea Decapoda Nephropidae) of different Mediterranean areas. Sci. Mar. 62 (Suppl. 1), 25-41.

Ridgway, ID, Taylor, AC, Atkinson, RJA, Chang, ES, Neil, DM, 2006. Impact of capture method and trawl duration on the health status of the Norway lobster, Nephrops norvegicus. Journal of Experimental Marine Biology and Ecology 339, 135-147.

Sala, A, Lucchetti, A, 2010. The effect of mesh configuration and codend circumference on selectivity in the Mediterranean trawl Nephrops fishery. Fisheries Research 103, 63-72.

Sala, A, Lucchetti, A, Piccinetti, C, Ferretti, M, 2008. Size selection by diamond- and squaremesh codends in multi-species Mediterranean demersal trawl fisheries. Fisheries Research 93, 8-21.

Sardà, F, Conan, GY, Fusté, X, 1993. Selectivity of Norway lobster Nephrops norvegicus (L.) in the northwestern Mediterranean. Scientia Marina 57, 167-174.

Sbragaglia, V., Leiva, D., Arias, A., García, J. A., Aguzzi, J. \& Breithaupt, T. (2017). Fighting over burrows: the emergence of dominance hierarchies in the Norway lobster (Nephrops norvegicus). Journal of Experimental Biology (in press). doi: $10.1242 /$ jeb.165969.

Schneider, RAZ, Huber, R, Moore, P, 2001. Individual and status recognition in the crayfish, Orconectes rusticus: the effects of urine release on fight dynamics. Behaviour 138, 137 153.

Sistiaga, M, Herrmann, B, Grimaldo, E, Larsen, RB, Tatone, I, 2015. Effect of lifting the sweeps on bottom trawling catch efficiency: A study based on the Northeast arctic cod (Gadus morhua) trawl fishery. Fisheries Research 167, 164-173.

Sistiaga, M, Herrmann, B, Grimaldo, E, O’Neill, FG, 2016a. Estimating the selectivity of unpaired trawl data: a case study with a pelagic gear. Scientia Marina 80, 321-327. 
460

Sistiaga, M, Herrmann, B, Grimaldo, E, Larsen, RB, Tatone, I, 2016b. The effect of sweep bottom contact on the catch efficiency of haddock (Melanogrammus aeglefinus). Fisheries Research 179, 302-307.

Stergiou, KI, Petrakis, G, Politou, CY, 1997. Size selectivity of diamond and square mesh cod-ends for Nephrops norvegicus in the Aegean Sea. Fisheries Research 29, 203-209.

Wienbeck, H., Herrmann, B., Feekings, J.P., Stepputtis, D., Moderhak, W., 2014. A comparative analysis of legislated and modified Baltic Sea trawl codends for simultaneously improving the size selection of cod (Gadus morhua) and plaice (Pleuronectes platessa). Fisheries Research 150, 28-37.

Wileman, D, Ferro, RST, Fonteyne, R, Millar, RB, 1996. Manual of methods of measuring the selectivity of towed fishing gears. ICES Cooperative Research Report No. 215., p. 132.

Winger, PD, Walsh, PJ, 2011. Selectivity, efficiency, and underwater observations of modified trap designs for the snow crab (Chionoecetes opilio) fishery in Newfoundland and Labrador. Fisheries Research 109, 107-113.

Xu, X, Millar, RB, 1993. Estimation of Trap Selectivity for Male Snow Crab (Chionoecetes opilio) Using the SELECT Modeling Approach with Unequal Sampling Effort. Canadian Journal of Fisheries and Aquatic Sciences 50, 2485-2490. 